\title{
VARIAÇÃO SAZONAL DO EPIFITISMO POR MACROALGAS EM UMA POPULAÇÃ̃O DE Sargassum vulgare C. AGARDH (PHAEOPHYCEAE, FUCALES) DA BAÍA DA ILHA GRANDE, RIO DE JANEIRO
}

\author{
Maria Teresa Menezes de Széchy ${ }^{1 *}$ \& Anderson Domenique Faria de Sál \\ 1. Laboratório Integrado de Ficologia, Departamento de Botânica, Instituto de Biologia, Centro de Ciências da Saúde, Universidade Federal do Rio de \\ Janeiro, Cidade Universitária, Rua Professor Rodolpho P. Rocco 211, bloco A, subsolo, sala 99. CEP: 21941902. Rio de Janeiro, RJ. \\ *E-mail:mtmszechy@gmail.com
}

\section{RESUMO}

O epifitismo é uma variável importante no estudo da estrutura das comunidades marinhas bentônicas. Em costões rochosos, o epifitismo por macroalgas resulta em maior número de estratos, heterogeneidade de habitats e diversidade específica, constituindo recursos diversos para a fauna associada. Variações temporais no número de espécies e na biomassa de macroalgas epífitas são descritas na literatura, sendo relacionadas, em alguns estudos, ao grau de desenvolvimento das macroalgas-substrato. Para a macroalga-substrato Sargassum, os estudos existentes não são suficientes para definir um padrão de relação entre o seu desenvolvimento vegetativo e o de suas epífitas. Este trabalho teve por objetivos descrever a variação sazonal em aspectos qualitativos e quantitativos de macroalgas epífitas em Sargassum vulgare de uma população de Angra dos Reis, Baía da Ilha Grande, Rio de Janeiro, e avaliar a relação do grau de epifitismo com o desenvolvimento vegetativo da macroalga-substrato. Coletas aleatórias de 20 indivíduos adultos de $S$. vulgare da praia das Gordas, Angra dos Reis, foram realizadas em fevereiro, maio, julho e outubro de 2001. As macroalgas epífitas, excetuando-se as calcárias crostosas, foram separadas por tipo morfofuncional, secas em estufa e pesadas. Foram identificadas 46 espécies de macroalgas (27 Rhodophyta, oito Ochrophyta e 11 Chlorophyta). Ceramiales (14 espécies) e tipo morfofuncional filamentoso (17 espécies) foram os grupos mais representativos em termos de número de espécies epífitas. O número de espécies de macroalgas epífitas por indivíduo de $S$. vulgare foi 7,6, em média. Jania adhaerens e $J$. capillacea foram as epífitas mais freqüentes ao longo do estudo. No verão, foram encontrados os maiores valores para massa seca de macroalgas epífitas, bem como para altura e massa úmida de $S$. vulgare; estas variáveis, no entanto, não mostraram relação linear entre si.

Palavras-chave: Baía da Ilha Grande, costão rochoso, epífitas, estrutura de comunidades, macroalgas, Sargassum, sazonalidade.

\begin{abstract}
SEASONAL VARIATION OF MACROALGAL EPIPHYTISM IN A Sargassum vulgare C. AGARDH (PHAEOPHYCEAE, FUCALES) POPULATION FROM ILHA GRANDE BAY, RIO DE JANEIRO. Epiphytism is an important variable to be considered in studies of marine benthic community structure. The epiphytism of macroalgae enhances stratification in rocky shores, leading to habitat heterogeneity, and increasing species diversity, due to greater diversification of the resources available to the associated fauna. There are records of temporal variations in the number of species and biomass of epiphytic macroalgae, and in some studies these variations were correlated with the degree of vegetative development of the host macroalga. Regarding the populations of Sargassum, the currently available information is insufficient to define relationship patterns between the vegetative development of Sargassum and its epiphytes. The present study aimed: 1) to describe seasonal variations in qualitative and quantitative aspects of the epiphytic macroalgae of a Sargassum vulgare population from the region of Angra dos Reis, Ilha Grande Bay, Rio de Janeiro State, Brazil; and 2) to assess the relationship between degree of epiphytism and vegetative development of the host macroalga. Twenty S. vulgare adult plants were randomly sampled from Gordas Beach in February, May, July and October 2001. Any epiphytic macroalga placed on their thalli were extracted, sorted, identified, classified into morphofunctiontal types, dehydrated and weighted. Apart from calcareous crusts, 46 species of macroalgae (27 Rhodophyta, eight Ochrophyta, and 11 Chlorophyta) were identified. The most numerous groups found were of the order Ceramiales (14 species) and of the filamentous morphofunctional type
\end{abstract}


(17 species). Jania adhaerens and Jania capillacea were the most frequently found epiphytic species in this study. The mean number of species of epiphytic macroalgae found on each Sargassum individual was 7.6. The greatest biomass of epiphytic macroalgae was found during summer, coinciding with the greatest height and wet mass values of $S$. vulgare. However, we detected no linear relationship between these variables.

Keywords: Community structure, epiphytes, Ilha Grande Bay, macroalgae, rocky shores, Sargassum, seasonality.

\section{INTRODUÇ̃̃O}

\section{EPIFITISMO NO AMBIENTE MARINHO}

Em comunidades marinhas bentônicas, organismos de diversos grupos taxonômicos, dimensões e níveis tróficos colonizam o talo de macroalgas ou as folhas de fanerógamas marinhas, o que se denomina epifitismo. O epifitismo resulta em maior número de estratos e maior heterogeneidade de habitats (Hicks 1980, Stewart 1982), representando um potencial de aumento da diversidade específica nestas comunidades (Menge \& Sutherland 1976, Krebs 1986).

Em costões rochosos, onde macroalgas são os organismos sésseis dominantes, os talos das macroalgas mais desenvolvidas servem de substrato para a fixação de bactérias, microalgas, outras macroalgas e diversos grupos de invertebrados (Round 1984). As macroalgas epífitas, além de contribuírem para a diversidade de espécies do local, também são importantes como produtores primários (Ballantine 1979). A cobertura de macroalgas epífitas, então, representa local de obtenção de recursos alimentares e de proteção/refúgio contra a incidência direta de radiação solar, a dessecação e a predação (Hayward 1980, Williams \& Seed 1992).

Para as macroalgas, o epifitismo é um tipo de vida comum (Chapman \& Chapman 1976), embora poucas espécies sejam epífitas obrigatórias (Edwards \& Kapraun 1973, Harlin 1973, Pearson \& Evans 1990, Ciciotte \& Thomas 1997). O epifitismo representa uma opção dentre as estratégias de colonização; macroalgas epífitas podem ter vantagens na competição por luz e por nutrientes (Lobban \& Harrison 1997), especialmente as de tipos morfofuncionais mais simples, como filamentosas e foliáceas (Steneck \& Dethier 1994). Macroalgas filamentosas e foliáceas são referidas como as mais freqüentes dentre as epífitas de outras macroalgas (Arrontes 1990, Figueiredo et al. 1997, Széchy \& Paula 1997).
O epifitismo em comunidades de costão rochoso é bastante variável quanto à composição, riqueza e abundância das espécies de epífitas. Esta variação pode ser notada em diferentes escalas espaciais e temporais (Rindi \& Guiry 2004), como o mencionado para outros componentes das comunidades bentônicas (Menconi et al. 1999, Benedetti-Cecchi 2001). Norton \& Burrows (1969) descrevem a variação sazonal da riqueza e composição de espécies de macroalgas epífitas em Saccorhiza polyschides (Lightf.) Batt., em costões rochosos na Grã-Bretanha. Suárez (1985) descreve a variação da diversidade de epífitas em Stypopodium zonale (Lamour.) Papenfuss, ao longo de um ano, na região sublitorânea rasa do litoral de Havana, Cuba.

Alguns estudos vinculam a variação no grau e tipo de epifitismo a condições do ambiente, como o nível de eutrofização (Kangas et al. 1982, Rönnberg \& Ruokolathi 1986), o grau de movimentação da massa d'água ou a pressão de herbivoria (Karez et al. 2000). Em geral, o grau de epifitismo é maior em locais mais protegidos do embate das ondas (Round 1984, Aguilar-Rosas \& Galindo 1990). No entanto, não existem padrões definidos para a variação espaço-temporal do epifitismo no meio marinho.

O grau de epifitismo também varia com a espécie da macroalga-substrato. Macroalgas diferem consideravelmente em sua adequação como substrato para as epífitas. Esta diferença pode ser relacionada à longevidade da espécie. Para algumas espécies estudadas, o epifitismo é mais intenso nas partes mais velhas do talo (Ballantine 1979, Aguilar-Rosas \& Galindo 1990). A adequação das macroalgas como substrato para epífitas também pode diferir em função de características morfológicas do talo, como grau de ramificação e rugosidade e textura da superfície, características bioquímicas, como produção de substâncias alelopáticas, e características fisiológicas, como liberação de mucilagem e taxa de crescimento do talo (Round 1984, Lobban \& Harrison 1997).

Muitas algas calcárias incrustantes perdem, em determinados momentos, suas células epiteliais, 
sugerindo que esta perda possa prevenir contra a colonização por outros organismos ("antifouling") ou ser simplesmente um meio destes organismos ficarem livres de células danificadas e de conceptáculos velhos (Littler \& Littler 1984, Keats et al. 1993). Keats et al. (1997) ilustraram, através de observações em microscopia eletrônica, a senescência e liberação de células epiteliais terminais de Hydrolithon onkodes (Heydrich) Penrose et Woelkerling, provando experimentalmente que este processo é um meio eficiente de redução de epifitismo.

Friedlander et al. (2001), ao estudarem as respostas de duas espécies de Gracilaria [Gracilaria lemaneiformis (Bory) Dawson, Acleto et Foldvik e um mutante de G. cornea J. Agardh] à presença ou não da epífita Ulva lactuca L., cultivadas em tanques externos, em meios com e sem antibióticos, indicaram a existência de defesas ao epifitismo em G. cornea, e não em G. lemaneiformis. Gracilaria cornea mostrou maiores taxas e crescimento de de liberação de hidrocarbonetos halogenados e peróxido de hidrogênio, substâncias sugeridas como as responsáveis pela atividade inibitória desta espécie.

Rindy \& Guiry (2004) detectaram maior abundância da epífita Polysiphonia lanosa (L.) Tandy nas partes mais velhas de Fucus vesiculosus L., vinculando este fato ao recrutamento preferencial de propágulos da espécie em partes danificadas do talo da macroalga-substrato, como em outros estudos (Lining \& Garbary 1992, Maggs \& Hommersand 1993). Um alto grau de epifitismo pode levar ao aumento da fragmentação ou do desprendimento do talo das macroalgassubstrato (Buschmann \& Gómez 1993). As epífitas podem provocar a redução da flexibilidade do talo das macroalgas-substrato, principalmente quando são incrustantes e calcificadas, podendo também reduzir as taxas de fotossíntese e de crescimento, em decorrência da competição por luz e nutrientes (Kangas et al. 1982, D’Antonio 1985, Buschmann \& Gómez 1993). Beach et al. (2003) mostram que os talos de algas verdes do gênero Halimeda, com mais de 50\% de cobertura por espécies de Dictyota, cresceram significativamente mais devagar quando comparados a talos sem estas epífitas.

Mais recentemente, a interferência do epifitismo sobre o desenvolvimento da macroalga-substrato tem sido analisada com enfoque no modo como as epífitas se fixam ao talo da macroalga-substrato, através de microscopias óptica e eletrônica. Leonardi et al. (2006) estudaram o epifitismo em uma espécie de Gracilaria cultivada no Chile ( $G$. chilensis Bird, McLachlan et Oliveira), enfocando o tipo de interação entre as macroalgas epífitas e a macroalgasubstrato, sua abundância relativa e variação temporal. Dos cinco tipos de interação descritos, foi destacado o tipo $\mathrm{V}$, em que as epífitas penetram no córtex e na medula, causando destruição de células da macroalga-substrato. Foi registrada a variação da abundância das epífitas, classificadas em diferentes tipos de interação, ao longo do ano. As epífitas do tipo V, como Ceramium spp. e Polysiphonia spp., mostraram um claro padrão sazonal, sendo mais abundantes no inverno. As epífitas dos tipos II (fortemente fixadas à superfície do talo da macroalgasubstrato, mas sem danos às suas células) e III (com penetração na camada cortical da macroalgasubstrato, mas sem danos às suas células) atingiram maiores percentagens de ocupação da macroalgasubstrato (até $90 \%$ do talo).

\section{Sargassum COMO MACROALGA-SUBSTRATO PARA EPÍFITAS}

A alga parda Sargassum C. Agardh (Phaeophyceae, Fucales) é considerada de morfologia complexa, com talo bem desenvolvido. Para espécies da costa brasileira, há citação de populações da região sublitorânea rasa com indivíduos atingindo $50 \mathrm{~cm}$ de altura ou mais. O talo de representantes de Sargassum pode tornar-se bastante ramificado, diferenciando ramos cilíndricos e porções achatadas (Paula 1988). Ao longo de sua ampla distribuição geográfica, há espécies anuais e espécies que vivem mais de um ano. Neste caso, os indivíduos perdem parte de seus ramos após o pico reprodutivo e senescência, regenerando-se posteriormente a partir das partes perenes do talo, que são o apressório (disco de fixação) e os ramos principais, que dele se diferenciam (Paula \& Oliveira Filho 1980, Széchy et al. 2006). A superfície do talo apresenta pouca mucilagem. Todas estas características criam condição favorável à fixação de outras macroalgas, ou seja, favorecem o epifitismo.

Sargassum tem ampla distribuição no Brasil (Paula 1988), sendo freqüente no litoral dos estados do Rio de Janeiro e São Paulo, em costões rochosos de locais moderados e protegidos em relação ao embate das 
ondas (Paula 1988, Széchy \& Paula 2000b). Nestes ambientes, esta macroalga pode formar bancos conspícuos na região sublitorânea rasa (Oliveira Filho \& Mayal 1976, Eston \& Bussab 1990, Széchy \& Paula 2000b).

Bancos de Sargassum mostram variação de abundância ao longo do ano (Ang Jr. 1985, Aguilar-Rosas \& Galindo 1990). Variação temporal da abundância de Sargassum também é descrita para algumas espécies da costa brasileira: Bombinhas, Santa Catarina (Dubiaski-Silva \& Masunari 2000); Ubatuba, São Paulo (Paula \& Oliveira Filho 1980, 1982, Eston \& Bussab 1990, Leite \& Turra 2003); Baía de Sepetiba (Amado Filho et al. 2003, Reis et al. 2003) e Arraial do Cabo (Godoy \& Coutinho 2002, Muniz et al. 2003), Rio de Janeiro; Pernambuco (Mansilla \& Pereira 1998). Para bancos de Sargassum da Baía da Ilha Grande, o menor desenvolvimento vegetativo, em relação à altura, número e massa seca de ramos laterais primários, foi observado no período do inverno (Széchy 1996, Széchy et al. 2006). Para explicar a variação na altura e massa seca das macroalgas ao longo do ano, fatores abióticos, como luz, temperatura e nutrientes, e fatores bióticos, como herbivoria, competição e epifitismo, são reconhecidos como importantes (Chapman 1995). Em banco de Sargassum cymosum C. Agardh de Ubatuba, São Paulo, algumas espécies de macroalgas, usualmente epilíticas, foram encontradas como epífitas no verão (Paula \& Oliveira Filho 1980). Em banco de S. vulgare C. Agardh de Arraial do Cabo, Rio de Janeiro, considerando os 41 táxons de categoria infragenérica de macroalgas epífitas (26 do filo Rhodophyta, nove Ochrophyta e seis Chlorophyta), o grau de epifitismo, avaliado pela biomassa, foi máximo também no verão (Muniz et al. 2003). Széchy \& Paula (1997), estudando epífitas em diferentes espécies de Sargassum, em populações de 12 locais nos estados do Rio de Janeiro e São Paulo, listam 81 táxons infragenéricos de macroalgas, pertencentes aos filos Rhodophyta, Ochrophyta e Chlorophyta. Dentre essas espécies, 59\% eram preferencialmente ou exclusivamente epífitas e 34 espécies eram filamentosas. Segundo estes autores, para $S$. vulgare na Ponta da Pitanga, Baía da Ilha Grande, Rio de Janeiro, o número médio de espécies epífitas, em quatro épocas de 1992, foi 7,5 por indivíduo.
As variações temporais no grau de desenvolvimento das macroalgas-substrato e no número de espécies e na biomassa de macroalgas epífitas são descritas para algumas espécies de Sargassum. No entanto, ainda não há dados suficientes que permitam definir um padrão para a relação entre o desenvolvimento vegetativo de Sargassum e o de suas epífitas. Para Sargassum cymosum de Ubatuba, São Paulo, o aumento do grau de epifitismo no verão foi relacionado ao maior número de ramos maduros e senescentes da macroalga-substrato (Paula \& Oliveira Filho 1980). Ainda em Ubatuba, foi encontrada relação inversa entre a biomassa de $S$. cymosum e a intensidade de epifitismo por espécies de Hypnea J.V. Lamour. (Leite \& Turra 2003). Por outro lado, na Baía de Sepetiba, foi obtida correlação positiva entre a abundância de Sargassum spp. e a epífita Hypnea musciformis (Wulfen in Jacq.) J.V. Lamour., que alcançaram pico de biomassa no período primavera/ verão (Reis et al. 2003).

Este estudo teve por objetivos descrever a variação sazonal em aspectos qualitativos e quantitativos de macroalgas epífitas em Sargassum vulgare de uma população de Angra dos Reis, Baía da Ilha Grande, Rio de Janeiro, e avaliar a relação do grau de epifitismo com o desenvolvimento vegetativo da macroalga-substrato.

Foram levantadas as seguintes hipóteses de estudo:

1) Seguindo o descrito para outras localidades, banco de Sargassum vulgare da Baía da Ilha Grande deve apresentar as rodófitas e o tipo morfofuncional filamentoso como os grupos mais representativos de epífitas, em termos de número de espécies;

2) No banco de Sargassum vulgare da Baía da Ilha Grande, indivíduos mais desenvolvidos em termos de altura e de biomassa devem ter maior grau de epifitismo;

3) O grau de epifitismo por macroalgas em banco de Sargassum vulgare da Baía de Ilha Grande deve mostrar variação temporal, simultaneamente às variações da macroalga-substrato, ou seja, deve haver relação linear entre estas duas variáveis.

\section{MATERIAL E MÉTODOS}

Foi estudada uma população de Sargassum vulgare da Praia das Gordas, próxima à cidade de Angra dos 
Reis (Figura 1). Esta praia situa-se logo após a Escola Naval, em frente à Ilha do Maia, sendo visitada por poucos banhistas, durante períodos de maré baixa.

A Praia das Gordas é considerada como moderadamente protegida, ou seja, mesmo estando dentro de enseada, é submetida à ação de ondas, particularmente quando há vento sudoeste. Blocos rochosos de diferentes dimensões servem de substrato para as macroalgas, na região sublitorânea rasa.

As coletas foram realizadas em área contínua de substrato rochoso, com aproximadamente $80 \mathrm{~m}$ de extensão horizontal, paralela à linha de costa, em quatro épocas do ano de 2001: fevereiro (verão), maio (outono), julho (inverno) e outubro (primavera). Vinte indivíduos adultos de Sargassum vulgare foram coletados em cada época do ano. Estas coletas foram realizadas aleatoriamente ao longo de uma corda de $20 \mathrm{~m}$ de comprimento, com 20 marcas posicionadas seguindo a Tabela de Números Aleatórios. Em cada época do ano, esta corda foi estendida sobre o banco de $S$. vulgare, paralelamente à linha da costa, a aproximadamente $1 \mathrm{~m}$ de distância do limite superior de distribuição da espécie. Os indivíduos de $S$. vulgare foram retirados do substrato rochoso com auxílio de espátula metálica, de modo destrutivo (ou seja, arrancando os indivíduos inteiros, inclusive os apressórios), e em seguida foram fixados em solução a $4 \%$ de formaldeído em água do mar. Cada indivíduo foi acondicionado em saco plástico.
No laboratório, cada indivíduo de Sargassum vulgare foi analisado sob microscópio estereoscópico, para a retirada das epífitas e dos demais organismos, com auxílio de pinça. Posteriormente a esta triagem, cada indivíduo de $S$. vulgare foi medido quanto à altura máxima do talo (da base do apressório ao ápice do maior ramo lateral primário) com régua, e foi pesado (massa úmida) em balança eletrônica (YMC Co. Ltda., Japão), com precisão de 0,01g.

As macroalgas epífitas de cada época do ano foram analisadas quanto a aspectos qualitativos e quantitativos. Como aspectos qualitativos do epifitismo, foram considerados: composição específica e classificação quanto ao tipo morfofuncional. Como aspectos quantitativos do epifitismo, foram considerados: freqüência das espécies, riqueza de espécies (número de espécies por indivíduo) e biomassa dos tipos morfofuncionais.

Para a identificação taxonômica, cortes histológicos das macroalgas epífitas foram realizados à mão livre com o auxílio de lâmina de barbear e observados em microscópio óptico. A identificação taxonômica tomou por base a chave artificial de Joly (1965), complementando-a com estudos mais recentes (e.g. Guimarães 2006). Para a atualização da nomenclatura, foi adotada a revisão de Wynne (2005). Seguiu-se Széchy \& Paula (1997), para a classificação das macroalgas epífitas quanto ao tipo morfofuncional.

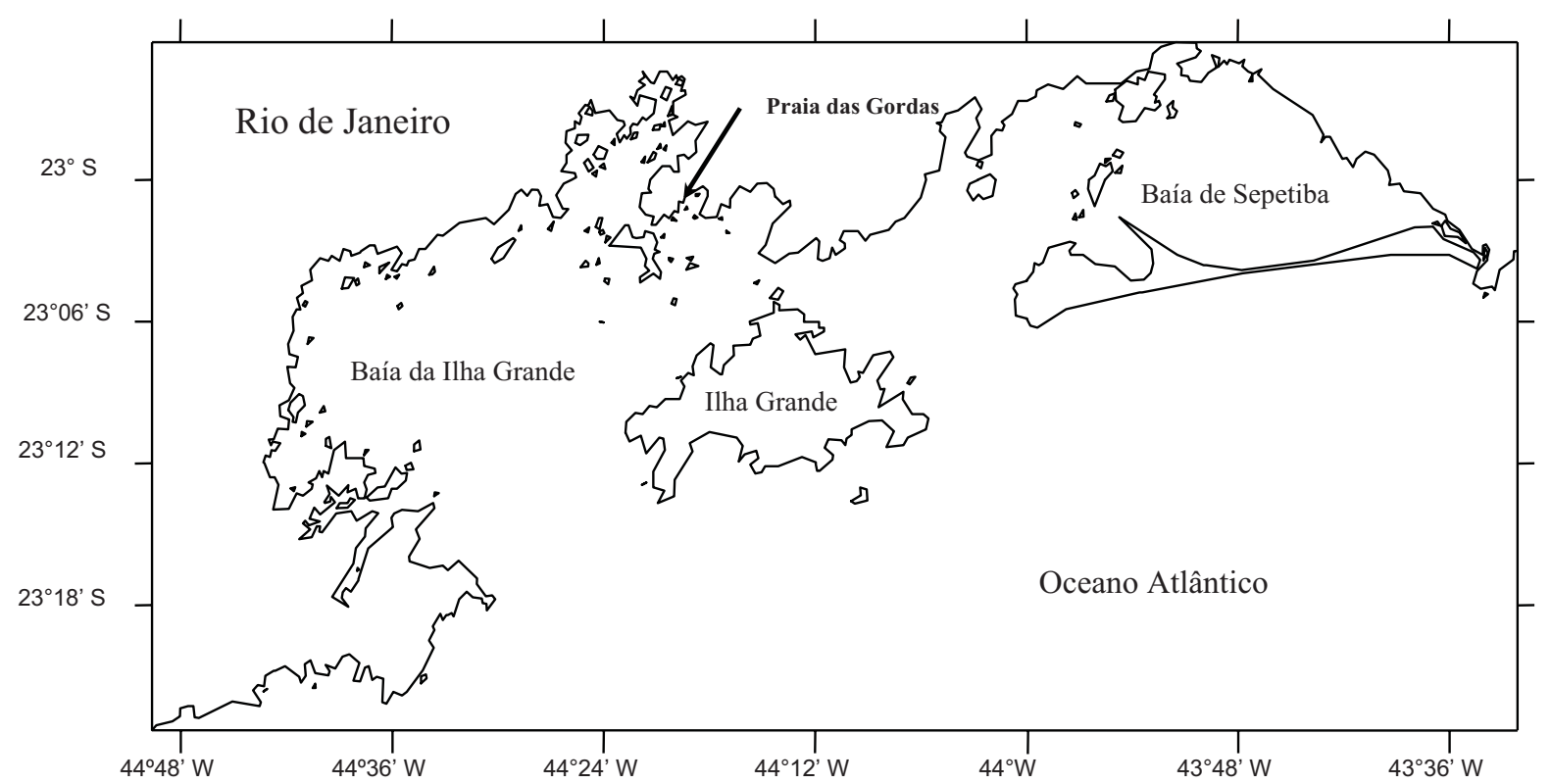

Figura 1. Localização geográfica da área de estudo: Praia das Gordas $(\rightarrow)$, Angra dos Reis, Rio de Janeiro.

Figure 1. Geographical location of the study area in the region of Angra dos Reis, Rio de Janeiro State, Brazil. The Praia das Gordas beach is indicated with an arrow. 
As macroalgas epífitas por indivíduo, agrupadas por tipo morfofuncional, permaneceram em estufa a $80^{\circ} \mathrm{C}$ por pelo menos quatro horas consecutivas, até atingirem massa constante, e depois foram pesadas em balança eletrônica (YMC Co. Ltda., Japão), com precisão de 0,01g. A presença de epífitas do tipo calcária crostosa foi computada, mas foi inviável a sua separação da macroalga-substrato para pesagem.

Para a classificação das espécies de macroalgas quanto à freqüência como epífitas em Sargassum vulgare, foram definidas quatro classes, com base na percentagem de ocorrência. A freqüência de cada espécie como epífita expressa, em percentagem, o número de indivíduos de Sargassum em que a espécie foi encontrada durante o estudo $(\mathrm{n}=80)$. A Tabela I estabelece a amplitude de freqüência para espécies de epífitas dentro das quatro classes: rara, pouco freqüente, freqüente e muito freqüente.

Tabela I. Classes de freqüência das espécies de macroalgas epífitas nos indivíduos de Sargassum vulgare.

Table I. Frequency classes of the epiphytic macroalgae found on Sargassum vulgare plants.

\begin{tabular}{lc}
\hline Freqüência das espécies de epífitas & $\%$ de ocorrência \\
\hline Rara & $0-25$ \\
Pouco freqüente & $26-50$ \\
Freqüente & $51-75$ \\
Muito freqüente & $76-100$ \\
\hline
\end{tabular}

\section{TRATAMENTO DOS DADOS}

A similaridade entre as épocas do ano quanto à freqüência das espécies de macroalgas epífitas foi estudada pela análise de grupamento hierárquico aglomerativo, com base no coeficiente de Bray-Curtis e método da associação média (Valentin 2000).

Os dados quantitativos foram avaliados pelo Teste de Shapiro-Wilk e de Lévene, quanto à normalidade e homogeneidade das variâncias, respectivamente. Os números de espécies de macroalgas epífitas por indivíduo de Sargassum vulgare foram comparados, entre as quatro épocas do ano, através da análise de variância unifatorial (ANOVA), seguida do teste de Tukey, para níveis de significância de 0,01 (Zar 1984). Os valores de biomassa das macroalgas epífitas foram analisados com base em gráficos de box plots, em função da ampla e heterogênea variabilidade dos dados.

Para avaliação da relação entre altura máxima do talo ou massa úmida dos indivíduos de Sargassum vulgare e de massa seca das suas epífitas, foram utilizados diagramas de dispersão.

\section{RESULTADOS E DISCUSSÃO}

\section{ASPECTOS QUALITATIVOS DO EPIFITISMO EM Sargassum vulgare}

Foram identificadas 46 espécies de macroalgas epífitas, pertencentes aos filos Rhodophyta (27 espécies), Ochrophyta (oito espécies) e Chlorophyta (11 espécies). Todas as espécies de macroalgas epífitas identificadas no presente estudo já foram citadas em levantamentos taxonômicos anteriores, realizados por Joly (1965), no litoral norte do estado de São Paulo, e por Széchy \& Paula (2000a), para a flora associada a bancos de Sargassum do litoral sudeste brasileiro. Dentre as 81 espécies de macroalgas epífitas em espécies de Sargassum dos estados de São Paulo e Rio de Janeiro, referidas por Széchy \& Paula (1997), $43 \%$ foram identificadas novamente como epífitas de Sargassum, na Praia das Gordas. Trinta e cinco por cento das espécies de macroalgas epífitas em Sargassum vulgare, identificadas por Muniz et al. (2003), para o litoral norte do estado do Rio de Janeiro, foram também observados no presente estudo.

A ordem mais representativa, quanto ao número de espécies de macroalgas epífitas, foi Ceramiales, com 14 espécies (Tabela II). O predomínio das espécies de macroalgas do filo Rhodophyta na Baía da Ilha Grande, bem como a maior representatividade de espécies da ordem Ceramiales, também foram mostrados por Falcão et al. (1992), Pedrini et al. (1994), Brito et al. (2002) e Muniz et al. (2003). A maior representatividade de espécies da ordem Ceramiales está de acordo com a flora citada para a região, por Széchy \& Nassar (2005).

O tipo morfofuncional mais representativo em número de espécies foi o filamentoso, com 17 espécies e, o menos representativo foi o das calcárias articuladas, com quatro espécies. Dentre os tipos morfofuncionais de macroalgas, somente as macrófitas coriáceas não foram encontradas como epífitas no presente estudo. $\mathrm{O}$ maior número de espécies de macroalgas epífitas filamentosas está de acordo com Széchy \& Paula (1997) e Muniz et al. (2003). Macroalgas filamentosas são caracterizadas pelas taxas elevadas de crescimento e reprodução que lhes conferem estratégias de espécies oportunistas, 
Tabela II. Classificação taxonômica e quanto ao tipo morfofuncional (tipo morf.) das macroalgas epífitas em Sargassum vulgare. CA = calcária articulada; Fi = filamentosa; Fo = foliácea; $\mathrm{M}$ = macrófita corticada. Observações: 1 - Espécimes não identificados em nível de espécie devido à falta de estruturas de reprodução; 2- Espécimes não identificados devido à escassez de material; * fases gametofítica e tetrasporofítica.

Table II. Taxonomic classification of the epiphytic macroalgae found on Sargassum vulgare plants and their morphofunctional type (tipo morf.). CA = articulate calcareous alga; $\mathrm{Fi}=$ filamentous alga; $\mathrm{Fo}=$ foliaceous alga; $M=$ Corticated macrophyte. Notes: 1 - Non-identified species due to lack of reproductive structures; 2 - Non-identified species due to paucity of specimens; * gametophytic and tetrasporophytic phases.

\begin{tabular}{l}
\hline Táxons \\
\hline RHODOPHYTA \\
Florideophyceae \\
Corallinales \\
Corallinaceae
\end{tabular}

Bonnemaisoniaceae

Ceramiales

Ceramiaceae

Rhodomelaceae

Gigartinales

Cystocloniaceae

Gigartinaceae

Rhodymeniales

Champiaceae

Lomentariaceae

OCHROPHYTA

Phaeophyceae

Dictyotales

Dictyotaceae

Sphacelariales

Sphacelariaceae
Jania adhaerens J.V. Lamour.

CA

Jania capillacea Harv.

Amphiroa beauvoisii J.V. Lamour.

CA

Amphiroa fragilissima (L.) J.V. Lamour.

$\mathrm{CA}$

Asparagopsis taxiformis (Delile) Trevis. *

Fi

Aglaothamnion cordatum (Börgesen) Feldm.-Maz.

$\mathrm{Fi}$

Centroceras clavulatum (C. Agardh in Kunth) Mont. in Durieu de Maison.

Ceramium comptum Börgesen

Ceramium flaccidum (Kütz.) Ardiss.

Ceramium vagans P.C. Silva

Spyridia filamentosa (Wulfen) Harv. in Hook.

Wrangelia argus (Mont.) Mont.

Tipo morf.

Acanthophora spicifera (Vahl) Börgesen

Chondria leptacremon (Melvill) De Toni

Chondrophycus papillosus (C. Agardh) Garbary \& J.T. Harper

Herposiphonia secunda (C. Agardh) Ambronn

Laurencia caduciramulosa Masuda \& Kawaguchi

Polysiphonia denudata (Dillwyn) Grev. ex Harv. in Hook.

Polysiphonia subtilissima Mont.

$\mathrm{Fi}$

$\mathrm{Fi}$

$\mathrm{Fi}$

$\mathrm{Fi}$

$\mathrm{Fi}$

$\mathrm{Fi}$

$\mathrm{M}$

$\mathrm{M}$

M

$\mathrm{Fi}$

M

$\mathrm{Fi}$

$\mathrm{Fi}$

Hypnea musciformis (Wulfen in Jacquin) J.V. Lamour.

M

Hypnea spinella (C. Agardh) Kütz.

Chondracanthus acicularis (Roth) Fredericq

$\mathrm{M}$

M

Champia parvula (C. Agardh) Harv.

$\mathrm{M}$

Champia sp. Kütz.

M

Gelidiopsis planicaulis (W.R. Taylor) W.R. Taylor

$\mathrm{M}$

Gelidiopsis variabilis (Grev. ex J Agardh) F. Schmitz

$\mathrm{M}$

Lomentaria corallicola Börgesen

Dictyopteris delicatula J.V. Lamour. $\quad$ Fo

Dictyota cervicornis Kütz. $\quad$ Fo

Dictyota ciliolata Sond. ex Kütz. Fo

Dictyota sp. ${ }^{1}$ Fo

Padina gymnospora (Kütz.) Sond. Fo

Sphacelaria rigidula Kütz. $\quad$ Fi

$\begin{array}{ll}\text { Sphacelaria } \text { spp. }{ }^{1} & \mathrm{Fi}\end{array}$ 
Tabela II (continuação):

Ectocarpales
Acinetosporaceae
Scytosiphonaceae
CHLOROPHYTA
Ulvophyceae
Ulvales
Ulvaceae

Ulvaceae

\section{Cladophorales}

Cladophoraceae

Bryopsidales

Bryopsidaceae

Caulerpaceae
Hincksia sp. ${ }^{1} \quad$ Fi

Chnoospora minima (K. Hering) Papenf. $\quad$ M

Ulva chaetomorphoides (Börgesen) H.S. Hayden, Blomster, Maggs, P.C. Silva,

Stanhope \& Waaland

Fo

Ulva compressa $\mathrm{L}$.

Ulva fasciata Delile

Ulva flexuosa Wulfen

Ulva lactuca $\mathrm{L}$.

Ulva rigida C. Agardh

Fo

Fo

Fo

Fo

Fo

$\mathrm{Fi}$

$\mathrm{Fi}$

Cladophora spp. ${ }^{2}$

Fi

Fi

Bryopsis plumosa (Huds.) C. Agardh

$\mathrm{Fi}$

Caulerpa fastigiata Mont.

Caulerpella ambigua (Okamura) Prud'homme \& Lokhorst geralmente de fases iniciais de sucessão (Steneck \& Dethier 1994). Sendo assim, macroalgas filamentosas estariam adaptadas a viverem sobre outras macroalgas, que corresponderiam a substratos de duração curta e sujeitos a diferentes graus de distúrbios.

Espécies filamentosas tiveram representatividade em todos os filos, principalmente no filo Rhodophyta. Espécies foliáceas foram representadas nos filos Ochrophyta e Chlorophyta, não tendo nenhum representante do filo Rhodophyta. As macrófitas corticadas e as calcárias articuladas foram, respectivamente, quase exclusivas ou exclusivas do filo Rhodophyta (Tabela III).

\section{ASPECTOS QUANTITATIVOS DO EPIFITISMO EM $\underline{\text { Sargassum vulgare }}$}

Jania adhaerens e Jania capillacea foram as epífitas mais freqüentes em Sargassum vulgare nas quatro estações do ano (Tabela IV). A maior freqüência de Jania adhaerens e Jania capillacea como epífita em $S$. vulgare discorda do descrito por Széchy \& Paula (1997, 2000a), que encontraram como epífitas mais freqüentes Hypnea musciformis e Dictyopteris delicatula. Para outras regiões biogeográficas, Rull \& Garreta (1989), ao estudarem a distribuição de algas sobre Cystoseira

Tabela III. Representatividade das macroalgas epífitas (de cada filo) em Sargassum vulgare, por tipo morfofuncional. Table III. Representativeness of epiphytic macroalgae (per phylum) on Sargassum vulgare according to morphofunctional type.

\begin{tabular}{|c|c|c|c|c|}
\hline \multirow[t]{2}{*}{ Tipos morfofuncionais } & \multicolumn{3}{|c|}{ Número de espécies } & \multirow[t]{2}{*}{$\Sigma=$} \\
\hline & Rhodophyta & Ochrophyta & Chlorophyta & \\
\hline Filamentosas & 11 & 2 & 5 & 18 \\
\hline Foliáceas & 0 & 5 & 6 & 11 \\
\hline Macrófitas corticadas & 12 & 1 & 0 & 13 \\
\hline Calcárias articuladas & 4 & 0 & 0 & 4 \\
\hline
\end{tabular}


mediterranea Sauv. (Fucales) da costa nordeste da Espanha, citam uma espécie de Jania [Jania rubens (L.) J. V. Lamour.] como a espécie mais freqüente de epífita do estipe. Rindi \& Guiry (2004), para a costa oeste da Irlanda, citam Elachista fucicola (Velley) Areschoug e Polysiphonia lanosa como as espécies mais freqüentes em Fucus vesiculosus (Fucales).

Outras rodófitas foram freqüentes, como: Ceramium flaccidum, Wrangelia argus, Polysiphonia subtilissima e Hypnea spinella. No entanto, a maioria das espécies foi rara como epífita em Sargassum vulgare (Tabela V); dentre estas, algumas espécies ocorreram somente em uma época do ano, tais como: Ceramium vagans, Spyridia filamentosa, Laurencia caduciramulosa, Champia parvula, Gelidiopsis planicaulis, Dictyopteris delicatula, Dictyota ciliolata, Ulva compressa, Caulerpa fastigiata e Caulerpella ambigua (Tabela IV). Outras espécies ocorreram com maior frequência em apenas um dos períodos avaliados, como no verão (Amphiroa fragilissima, Acanthophora spicifera, Herposiphonia secunda, Champia sp., Ulvaflexuosa) ou na primavera (Asparagopsis taxiformis) (Tabela IV).

Analisando as macroalgas epífitas em Sargassum vulgare, quanto à frequência, nas quatro épocas do ano, observamos que, apesar dos baixos valores de similaridade $(<70 \%)$, as épocas do ano mais similares entre si foram outono e primavera; verão foi a época do ano que mais se distanciou das demais (Figura 2).

Se a comparação entre as épocas do ano for feita com base na freqüência das espécies epífitas, agru- padas por tipos morfofuncionais, nota-se que houve ligeira alteração da proporção entre os tipos morfofuncionais ao longo do ano. No verão, houve distribuição mais homogênea na ocorrência de epífitas dos diferentes tipos morfofuncionais; em relação às outras épocas do ano, as freqüências relativas das foliáceas e das macrófitas corticadas aumentaram. Epífitas filamentosas foram relativamente mais freqüentes na primavera, enquanto as calcárias articuladas o foram no inverno (Figura 3).

A riqueza de espécies de macroalgas epífitas em Sargassum vulgare variou de 21, no inverno, a 29, no verão (Tabela VI). Esta riqueza de espécies de epífitas mostra que $S$. vulgare representa, na Baía da Ilha Grande, habitat favorável ao desenvolvimento da macroflora ficológica, concordando com Széchy \& Paula (1997, 2000a).

Foi verificada diferença significativa no número de espécies de macroalgas epífitas por macroalga-substrato entre as épocas do ano (ANOVA: $F=8,83 ; p<0,01$ ). No verão, o número foi, em média, significativamente maior do que o observado no inverno $(\mathrm{F}=0,0002)$ e no outono $(\mathrm{F}=$ 0,0013 ) (Teste de Tukey, $\mathrm{n}=20$ ). O número maior de espécies de macroalgas epífitas no verão (até 16 espécies de epífitas por indivíduo) concorda com o observado por Paula \& Oliveira Filho (1980), que relacionaram este aumento ao maior número de ramos maduros e senescentes do Sargassum. Maior número de espécies de epífitas no verão foi também observado por Rindi \& Guiry (2006); no entanto, estes autores encontraram menor número

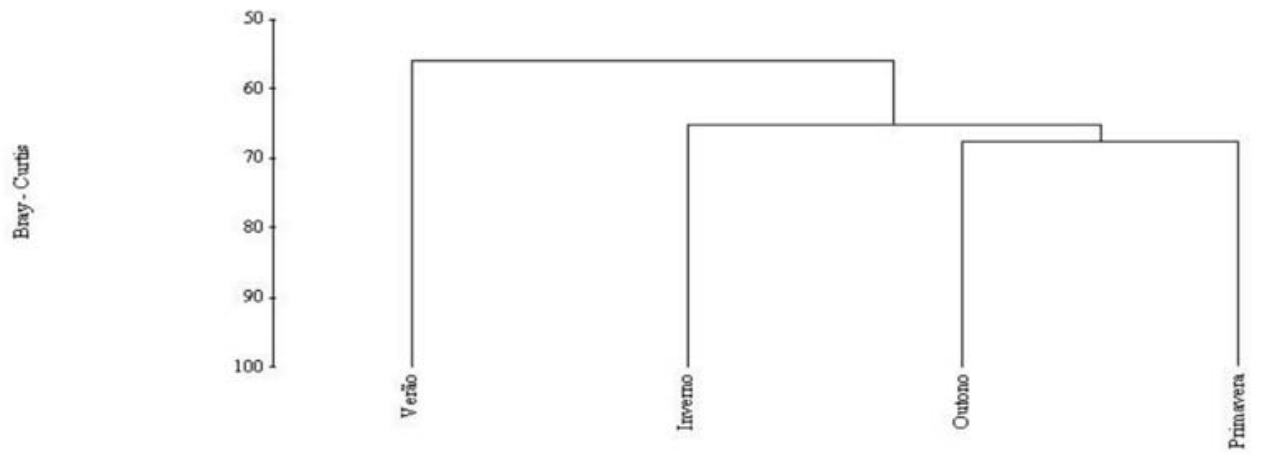

Figura 2. Análise de grupamento das quatro estações do ano, quanto à freqüência das espécies epífitas em Sargassum vulgare da Praia das Gordas, Angra dos Reis, RJ. Coeficiente de similaridade de Bray-Curtis aplicado aos dados não transformados, pelo método de associação média (UPGMA). Figure 2.Cluster analysis showing the similarity among the four seasons, based on the frequency of the epiphytic macroalgae species on Sargassum vulgare from Praia das Gordas, Angra dos Reis, RJ. The Bray-Curtis coefficient was applied to non-transformed data, by the UPGMA method. 
Tabela IV. Número de indivíduos de Sargassum vulgare em que cada espécie de macroalga ocorreu como epífita, por época do ano. V= verão; O= outono; $\mathrm{I}=$ inverno; $\mathrm{P}=$ primavera.

Table IV. Number of Sargassum vulgare plants on which each macroalga species was found, in the different seasons. $V=$ Summer; $O=A u t u m n ; I=$ Winter; $P=$ Spring.

\begin{tabular}{|c|c|c|c|c|}
\hline \multirow[b]{2}{*}{ Espécie } & \multicolumn{4}{|c|}{$\begin{array}{c}\mathrm{N}^{\mathrm{o}} \text { de indivíduos de Sargassum vulgare em que } \\
\text { ocorreu como epífita }\end{array}$} \\
\hline & $\mathrm{V}$ & $\mathrm{O}$ & $\mathrm{I}$ & $\mathrm{P}$ \\
\hline Jania adhaerens & 19 & 17 & 17 & 19 \\
\hline Jania capillacea & 19 & 18 & 16 & 19 \\
\hline Amphiroa beauvoisii & 8 & 8 & 10 & 7 \\
\hline Amphiroa fragilissima & 14 & 2 & 8 & 3 \\
\hline Asparagopsis taxiformis & 6 & 5 & 2 & 13 \\
\hline Aglaothamnion cordatum & 1 & 0 & 1 & 0 \\
\hline Centroceras clavulatum & 2 & 4 & 0 & 2 \\
\hline Ceramium comptum & 0 & 0 & 2 & 2 \\
\hline Ceramium flaccidum & 16 & 18 & 9 & 9 \\
\hline Ceramium vagans & 0 & 0 & 1 & 0 \\
\hline Ceramium spp. & 0 & 1 & 0 & 0 \\
\hline Spyridia filamentosa & 0 & 0 & 0 & 2 \\
\hline Wrangelia argus & 10 & 8 & 14 & 19 \\
\hline Acanthophora spicifera & 7 & 2 & 0 & 3 \\
\hline Chondria leptacremon & 3 & 1 & 0 & 0 \\
\hline Chondrophycus papillosus & 1 & 0 & 0 & 0 \\
\hline Herposiphonia secunda & 13 & 2 & 5 & 8 \\
\hline Laurencia caduciramulosa & 12 & 0 & 0 & 0 \\
\hline Polysiphonia denudata & 1 & 4 & 1 & 2 \\
\hline Polysiphonia subtilissima & 0 & 12 & 12 & 15 \\
\hline Hypnea musciformis & 0 & 1 & 0 & 0 \\
\hline Hypnea spinella & 15 & 10 & 4 & 11 \\
\hline Chondracanthus acicularis & 0 & 0 & 0 & 1 \\
\hline Champia parvula & 0 & 0 & 0 & 5 \\
\hline Champia sp. & 12 & 5 & 8 & 5 \\
\hline Gelidiopsis planicaulis & 0 & 0 & 1 & 0 \\
\hline Gelidiopsis variabilis & 0 & 1 & 0 & 1 \\
\hline Lomentaria corallicola & 3 & 1 & 0 & 2 \\
\hline Dictyopteris delicatula & 0 & 1 & 0 & 0 \\
\hline Dictyota cervicornis & 0 & 1 & 0 & 4 \\
\hline Dictyota ciliolata & 0 & 0 & 0 & 2 \\
\hline Dictyota $\mathrm{sp}$ & 7 & 5 & 0 & 1 \\
\hline Padina gymnospora & 2 & 0 & 0 & 0 \\
\hline Sphacelaria rigidula & 0 & 0 & 1 & 1 \\
\hline Sphacelaria spp. & 1 & 0 & 0 & 1 \\
\hline Hincksia sp. & 0 & 0 & 0 & 1 \\
\hline Chnoospora mínima & 1 & 0 & 0 & 0 \\
\hline Ulva chaetomorphoides & 1 & 0 & 0 & 0 \\
\hline Ulva compressa & 4 & 0 & 0 & 0 \\
\hline Ulva fasciata & 0 & 2 & 0 & 0 \\
\hline Ulva flexuosa & 14 & 2 & 2 & 1 \\
\hline Ulva lactuca & 1 & 0 & 0 & 0 \\
\hline Ulva rigida & 1 & 0 & 0 & 0 \\
\hline Cladophora vagabunda & 0 & 4 & 1 & 1 \\
\hline Cladophora spp. & 15 & 2 & 7 & 3 \\
\hline Bryopsis pennata & 0 & 0 & 1 & 0 \\
\hline Bryopsis plumosa & 1 & 0 & 2 & 0 \\
\hline Caulerpa fastigiata & 0 & 0 & 0 & 4 \\
\hline Caulerpella ambigua & 0 & 0 & 0 & 2 \\
\hline
\end{tabular}


Tabela V. Classificação das espécies de macroalgas epífitas em Sargassum vulgare quanto à freqüência ao longo de um ano. Table V. Classification of species of epiphytic macroalgae on Sargassum vulgare in relation to frequencies during the year.

\begin{tabular}{lllll}
\hline Frequência & N. de spp. & Espécies & & \\
\hline Muito freqüentes & 2 & Jania adhaerens & Jania capillacea & \\
Freqüentes & 4 & C. flaccidum & P. subtilissima & \\
Pouco freqüentes & 5 & Wrangelia argus & Hypnea spinella & \\
& & A. beauvoisii & A. taxiformis & Champia sp. \\
& & A. fragilissima & H. secunda & \\
& & A. cordatum & Champia parvula & Chnoospora minima \\
& C. clavulatum & G. planicaulis & U.chaetomorphoides \\
& C. comptum & G. variabilis & Ulva compressa \\
& Ceramium vagans & L. corallicola & Ulva fasciata \\
& S. filamentosa & C. acicularis & Ulva flexuosa \\
& A. spicifera & D. delicatula & Ulva lactuca \\
& C. leptacremon & D. cervicornis & Ulva rigida \\
& C. papillosus & Dictyota ciliolata & C. vagabunda \\
& L. caduciramulosa & Dictyota sp. & Bryopsis pennata \\
& P. denudata & P. gymnospora & Bryopsis plumosa \\
& & S. rigidula & Caulerpa fastigiata \\
& & Hincksia sp. & Caulerpella ambigua \\
\hline & & &
\end{tabular}

de espécies na Irlanda (16) do que o encontrado neste estudo.

O número médio de espécies de macroalgas epífitas por indivíduo de Sargassum vulgare ao longo do estudo foi de 7,6, similar ao citado por Széchy \& Paula (1997), para diferentes espécies de Sargassum de locais do litoral sudeste brasileiro.

A massa seca total de macroalgas epífitas por indivíduo de Sargassum vulgare mostrou tendência de declínio do verão em direção ao inverno. A amplitude de variação dos valores de biomassa das epífitas foi grande, especialmente no verão e no outono, em contraste com a amplitude de variação no inverno e na primavera (Figura 4).

A massa seca das macroalgas epífitas por tipo morfofuncional também apresentou grande amplitude de variação ao longo do estudo, particularmente para as calcárias articuladas. Foi verificada novamente tendência de declínio da biomassa do verão em direção ao inverno, principalmente para as macrófitas corticadas e para as calcárias articuladas (Figura 5).

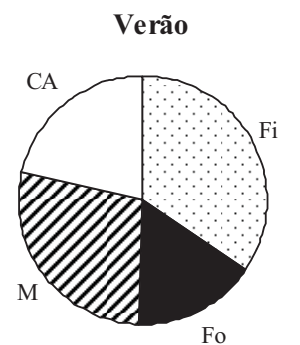

Inverno

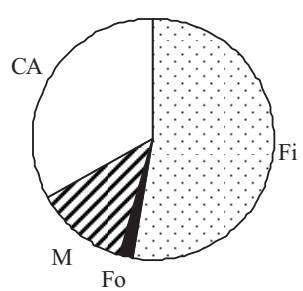

Figura 3. Freqüência relativa das espécies de macroalgas epífitas em Sargassum vulgare, por tipos morfofuncionais, nas quatro épocas do ano. $\mathrm{Fi}=$ Filamentosas; $\mathrm{Fo}=$ Foliáceas; $\mathrm{M}=$ macrófitas corticadas; $\mathrm{CA}=$ calcárias articuladas.

Figure 3. Relative frequency of epiphytic macroalgae species on Sargassum vulgare, according to morphofunctional types, in the seasons. $F i=$ filamentous alga; $F o=$ foliaceous alga; $M=$ corticated macrophytes; $C A=$ articulated calcareous alga. 
Tabela VI. Número de espécies de macroalgas epífitas em Sargassum vulgare, nas quatro épocas do ano $(\mathrm{V}=$ verão; $\mathrm{O}=$ outono; $\mathrm{I}=$ inverno; $\mathrm{P}=$ primavera).

Table VI. Number of epiphytic macroalgae species on Sargassum vulgare during the year ( $V=$ Summer; $O=$ Autumn; $I=$ Winter; $P=$ Spring. $)$

\begin{tabular}{lcccc}
\hline Número de espécies epífitas & $\mathrm{V}$ & $\mathrm{O}$ & $\mathrm{I}$ & $\mathrm{P}$ \\
\hline Total & 29 & 23 & 21 & 28 \\
Rhodophyta & 18 & 18 & 16 & 20 \\
Ochrophyta & 4 & 2 & 1 & 4 \\
Chlorophyta & 7 & 3 & 4 & 4 \\
\hline
\end{tabular}

A maior abundância de epífitas no verão também foi documentada por Rindi \& Guiry (2004), em estudo realizado no oeste da Irlanda sobre a variabilidade espaço-temporal na composição específica e cobertura de macroalgas epífitas em Fucus vesiculosus. Estes autores sugerem que o principal fator responsável pela distribuição das epífitas é o padrão fenológico de cada espécie, o que determina a disponibilidade de propágulos ao longo do ano, e a dispersão destes propágulos em escala espacial.

O conhecimento da flora epifítica pode ser uma ferramenta a mais para a avaliação de qualidade ambiental. Estudos em outras áreas geográficas têm mostrado que algumas macroalgas epífitas podem ser beneficiadas em ambientes eutrofizados, aumentando sua abundância de modo expressivo, o que leva à diminuição das chances de crescimento de outras espécies epífitas e, conseqüentemente à diminuição da biodiversidade (Hoffmann et al. 1994).

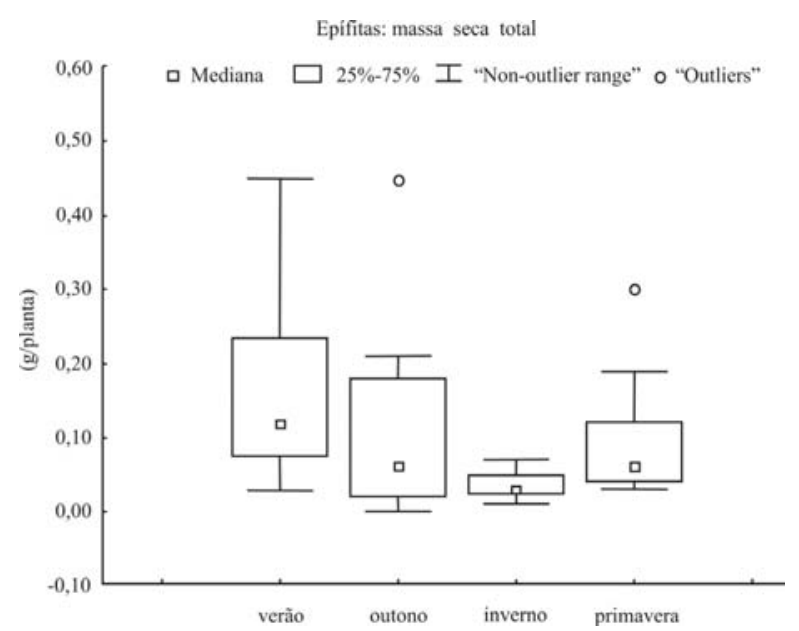

Figura 4. Massa seca total das macroalgas epífitas por indivíduo de Sargassum vulgare, por época do ano (valores medianos e amplitude de variação, $\mathrm{n}=20$ ).

Figure 4. Total dry mass of epiphytic macroalgae per Sargassum vulgare plant in the seasons (median values and variation range, $n=20$ ).

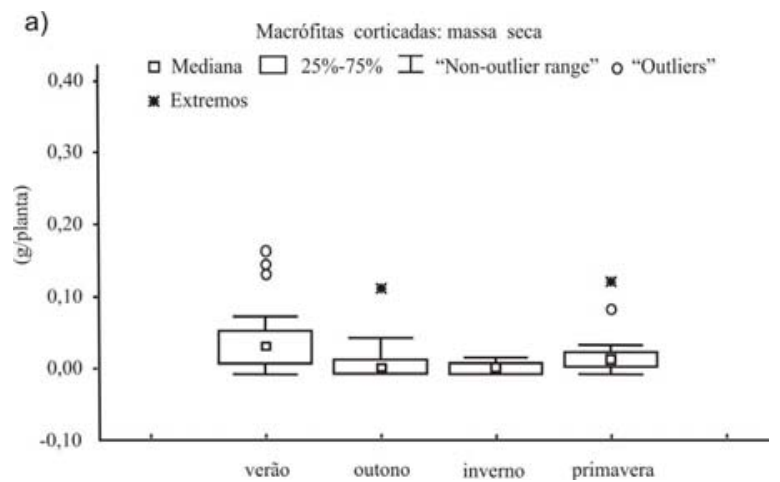

b)

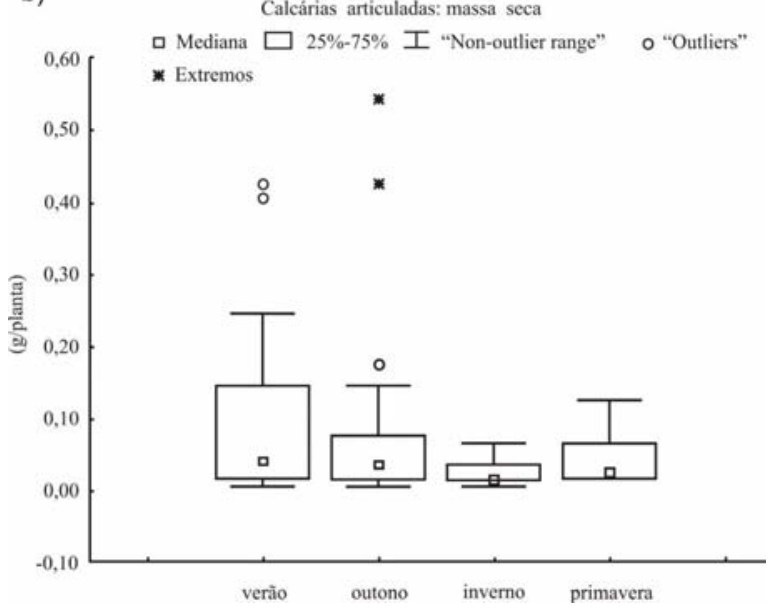

Figura 5. Massa seca de macroalgas epífitas dos tipos morfofuncionais mais representativos (gramas por indivíduo de Sargassum vulgare), nas quatro épocas do ano (valores medianos e amplitude de variação, $\mathrm{n}=20$ ). Figure 5. Dry mass of the most abundant morphofunctional types of epiphytic macroalgae on Sargassum vulgare (dry mass per Sargassum vulgare plant) in the seasons (median values and variation range, $n=$ 20)

\section{MACROALGA-SUBSTRATO (Sargassum vulgare)}

A população de Sargassum vulgare da Praia das Gordas mostrou pico de desenvolvimento vegetativo no verão, quando foram observados valores máximos de altura $(32,5 \mathrm{~cm})$ e massa úmida $(22,2 \mathrm{~g})$ dos indivíduos. Os valores medianos nitidamente diminuíram do verão para as outras épocas do ano (Figura 6). Padrão de variação sazonal similar ao da população de $S$. vulgare da Praia das Gordas foi descrito para espécies de Sargassum do litoral sudeste por outros autores (Széchy et al. 2006).

\section{RELAÇÃO ENTRE O GRAU DE EPIFITISMO E O DESENVOLVIMENTO VEGETATIVO DE Sargassum vulgare}

O período de menor grau de desenvolvimento vegetativo das macroalgas-substrato (inverno) coincidiu com o período de menor riqueza de espécies epífitas. 


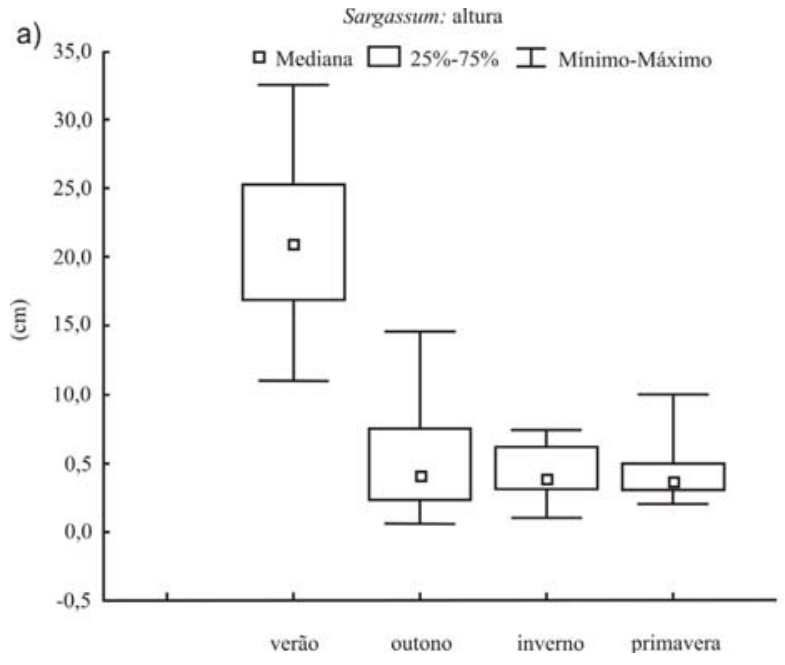

b)

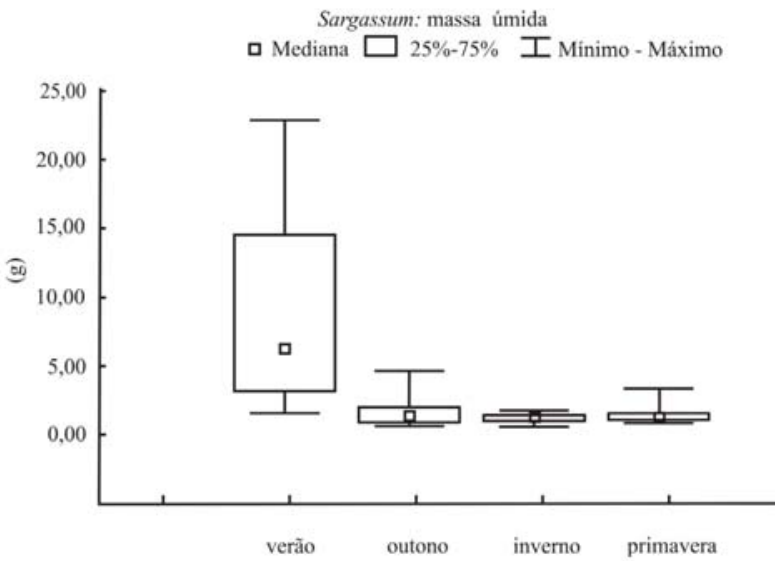

Figura 6. Desenvolvimento vegetativo de Sargassum vulgare, ao longo do ano, na Praia das Gordas. Altura dos indivíduos (cm); Massa úmida dos indivíduos ( $\mathrm{g}$ ) (valores medianos e amplitude de variação, $\mathrm{n}=20$ ).

Figure 6. Vegetative development of Sargassum vulgare during the year in Praia das Gordas beach. plant height (cm); wet mass of the plants ( $\mathrm{g}$ ) (median values and variation range, $n=20$ ).
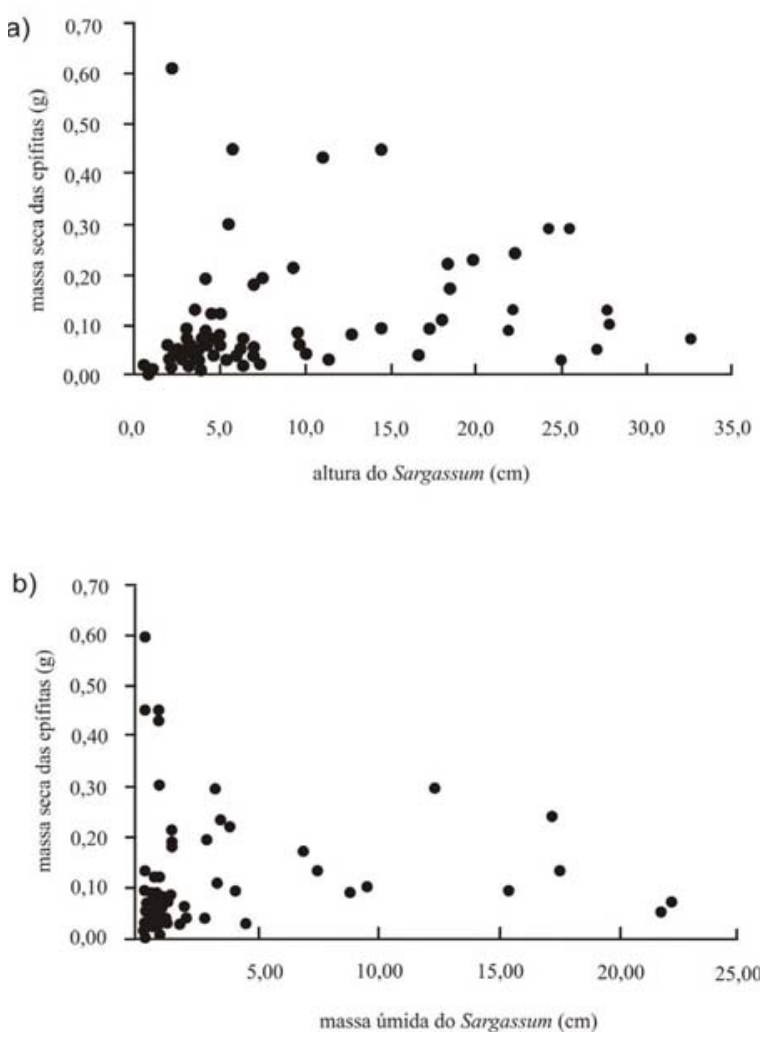

Figura 7. Relação entre a massa seca total de macroalgas epífitas e o desenvolvimento vegetativo da macroalga-substrato, em função de duas variáveis. Altura de Sargassum vulgare $(\mathrm{cm})$; Massa úmida de Sargassum vulgare $(\mathrm{g})$

Figure 7. Relationship between total dry mass of epiphytic macroalgae and the vegetative development of the host macroalga, based on the two variables: height of Sargassum vulgare $(\mathrm{cm})$; wet mass of Sargassum vulgare $(\mathrm{g})$
O período de maior grau de desenvolvimento vegetativo da macroalga-substrato (verão) coincidiu com o período de maiores valores para massa seca de macroalgas epífitas. Reis et al. (2003) indicam relação positiva entre as biomassas de espécies de Sargassum e a epífita Hypnea musciformis. No entanto, a relação macroalgasubstrato e epífita nem sempre é positiva, como exemplificam D'Antonio (1985).

Apesar desta coincidência entre o grau de epifitismo, avaliado com base na biomassa, e o desenvolvimento vegetativo da macroalgasubstrato, os diagramas de dispersão não indicaram relação linear entre estas variáveis (Figura 7). Este resultado contrasta com os de outros estudos.

\section{CONCLUSÕES}

O grau de epifitismo em Sargassum vulgare, quando avaliado através da massa seca dos diferentes tipos morfofuncionais de macroalgas, mostra grande amplitude de variação entre indivíduos da macroalga-substrato, no mesmo local e na mesma época do ano.

Apesar do pico de altura e biomassa de Sargassum vulgare e de massa seca de suas epífitas serem coincidentes em alguns momentos, não existe relação linear entre o grau de desenvolvimento vegetativo de $S$. vulgare e a abundância das epífitas. Isto indica 
a complexidade da interação macroalga-substrato e epífitas, sugerindo a influência de muitos fatores nesta interação.

\section{REFERÊNCIAS BIBLIOGRÁFICAS}

AGUILAR-ROSAS, R. \& GALINDO, A.M. 1990. Ecological aspects of Sargassum muticum (Fucales, Phaeophyta) in Baja California: reproductive phenology and epiphytes. Hydrobiologia, 204/205: 185-190.

AMADO FILHO, G.M.; BARRETO, M.B.B.B.; MARINS, B.V.; FÉLIX, C. \& REIS, R.P. 2003. Estrutura de comunidades fitobentônicas do infralitoral da Baía de Sepetiba, RJ, Brasil. Revista Brasileira de Botânica, 26: 329-342.

ANG Jr., P.O. 1985. Phenology of Sargassum siliquosum J. Ag. and S. paniculatum J. Ag. (Sargassaceae, Phaeophyta) in the reef flat of Balibago (Calatagan, Philippines). Pp 51-57. In: Proceedings of the V International Coral Reef Congress. Tahiti. v. 5.

ARRONTES, J. 1990. Composition, distribution on host, and seasonality of epiphytes on three intertidal algae. Botanica Marina, 33: 205-211.

BALLANTINE, D.L. 1979. The distribution of algal epiphytes on macrophyte hosts offshore of La Parguera, Puerto Rico. Botanica Marina, 22: 107-111.

BEACH, K.; WALTERS, L.; BORGES, H.; SMITH, C.; COYER, J. \& VROOM, P. 2003. The impact of Dyctyota spp. on Halimeda populations of Conch Reef, Florida keys. Journal of Experimental Marine Biology and Ecology, 297: 141-159.

BENEDETTI-CECCHI, L. 2001. Variability in abundance of algae and invertebrates at different spatial scales on rocky sea shores. Marine Ecology Progress Series, 215: 79-92.

BRITO, L.V.R.; SZÉCHY, M.T.M. \& CASSANO, V. 2002. Levantamento taxonômico das macroalgas da zona das marés de costões rochosos adjacentes ao Terminal Almirante Maximiano Fonseca, Baía da Ilha Grande, R.J. Atlântica, 24: 17-26.

BUSCHMANN, A.H. \& GÓMEZ, P. 1993. Interactions mechanisms between Gracilaria chilensis (Rhodophyta) and epiphytes. Hydrobiologia, 260/261: 345-351.

CHAPMAN, A.R.O. 1995. Functional ecology of fucoid algae: twenty-three years of progress. Phycologia, 34:1-32.

CHAPMAN, V.J. \& CHAPMAN, D.J. 1976. Life forms in the algae. Botanica Marina, 19: 65-74.

CICIOTTE, S.L. \& THOMAS, R.J. 1997. Carbon exchange between Polysiphonia lanosa (Rhodophyceae) and its brown algal host. American Journal of Botany, 84: 1614-1616.

D'ANTONIO, C. 1985. Epiphytes on the rocky intertidal red alga Rhodomela larix (Turner) C. Agardh: negative effects on the host and food for herbivores? Journal of Experimental Marine Biology and Ecology, 86: 197218.
DUBIASKI-SILVA, J. \& MASUNARI, S. 2000. Variação sazonal e vertical da biomassa de Sargassum cymosum C. Agardh, 1820 (Phaeophyta) e da densidade de sua fauna vágil na Ponta de Garoupas, Bombinhas, Santa Catarina. Publicações da Academia de Ciências do Estado de São Paulo, 109: 110-117.

EDWARDS, P. \& KAPRAUN, D.F. 1973. Benthic marine algal ecology in the port Aransas, Texas area. Contributions to Marine Sciences, University of Texas, 17: 15-57.

ESTON, V.R. \& BUSSAB, W.O. 1990. An experimental analysis of ecological dominance in a rocky subtidal macroalgal community. Journal of experimental marine Biology and Ecology, 136: 170-195.

FALCÃO, C.; MAURAT, M.C.; NASSAR, C.A.G.; SZÉCHY, M.T.M. \& MITCHELL, G.J.P. 1992. Benthic marine flora of the northeastern and southeastern coast of Ilha Grande, Rio de Janeiro, Brazil: phytogeographic considerations. Botanica Marina, 35: 357-364.

FIGUEIREDO, M.A. de O.; NORTON, T.A. \& KAIN, J.M. 1997. Settlement and survival of epiphytes on two intertidal crustose coralline algae. Journal of experimental marine Biology and Ecology, 213: 247260.

FRIEDLANDER, M.; KASHMAN, Y.; WEINBERG, F. \& DAWES, C.J. 2001. Gracilaria and its epiphytes:4The response of two Gracilaria species to Ulva lactuca in a bacteria-limited environment. Journal of Applied Phycology, 13: 501-507.

GODOY, E.A.S. \& COUTINHO, R. 2002. Can artifical beds of plastic mimics compensate for seasonal absence of natural beds of Sargassum furcatum? ICES Journal of Marine Sciences, 59: 111-115.

GUIMARÃES, S.M.P. de B. 2006. A revised checklist of benthic marine Rhodophyta from the state of Espírito Santo, Brazil. Boletim do Instituto de Botânica, 17: 145-194.

HARLIN, M.M. 1973. Transfer of products between epiphytic marine algae and host plants. Journal of Phycology, 9: 243-248.

HAYWARD, P.J. 1980. Invertebrate epiphytes of coastal marine algae. Chap. 11, Pp 761-787. In: J.H. Price; D.E.G. Irvine \& W.F. Farnham, (eds.), The shore environment, vol. 2: ecosystems. Academic Press, London. 945p.

HICKS, G.R.F. 1980. Structure of phytal harpacticoid copepod assemblages and the influence of habitat complexity and turbidity. Journal of experimental marine Biology and Ecology, 44: 157-192.

HOFFMANN, L.; DETIENNE, X. \& DEMOULIN, V. 1994. Studies of marine epiphytic algae, Calvi, Corsica, III: Variations in the population of epiphytic Bangiophyceae. Cryptogamie Algologie, 15: 53-63.

JOLY, A.B. 1965. Flora marinha do litoral norte do Estado de São Paulo e regiões circunvizinhas. Boletim da Faculdade de Filosofia, Ciências e Letras da Universidade de São Paulo, (294) Botânica, 21: 1-393.

KANGAS, P.; AUTIO, H.; HÄLLFORS, G.; LUTHER, H.; NIEMI, A. \& SALEMAA, H. 1982. A general model of 
the decline of Fucus vesiculosus at Tuärminne, south coast of Finland in 1977-81. Acta Botanica Fennica, 118: 1-27.

KAREZ, R.; ENGELBERT, S. \& SOMMER, U. 2000. "Co-consumption" and "protective coating": two new proposed effects of epiphytes on their macroalgal hosts in mesograzer-epiphyte-host interactions. Marine Ecology Progress Series, 205: 85-93.

KEATS, D.W.; GROENER, A. \& CHAMBERLAIN, Y.M. 1993. Cell sloughing in the littoral zone coralline alga, Spongites yendoi (Foslie) Chamberlain (Corallinales, Rhodophyta). Phycologia, 32 (2): 143-150.

KEATS, D.W.; KNIGHT, M.A. \& PUESCHEL, C.M. 1997. Antifouling effects of epithallial shedding in three crustose coralline algae (Rhodophyta, Corallinales) on a coral reef. Journal of experimental marine Biology and Ecology, 213: 281-293.

KREBS, C.J. 1986. Ecologia. Ed. Pirámide, Madri. 782p.

LEITE, F.P.P. \& TURRA, A. 2003. Temporal variation in Sargassum biomass, Hypnea epiphytism and associated fauna. Brazilian Archives of Biology and Technology, 46: 665-671.

LEONARDI, P.I.; MIRAVALLES, A.B.; FAUGERON, S.A.; FLORES, V.; BÉLTRAN, J. \& CORREA, J.A. 2006. Diversirty, phenomenology and epidemiology of epiphytism in farmed Gracilaria chilensis (Rhodophyta) in northern Chile. European Journal of Phycology, 41 (2): 247-257.

LINING, T. \& GARBARY, D.J. 1992. The Ascophyllum/ Polysiphonial Mycosphaerella symbiosis. III. Experimental studies on the interactions between $P$. lanosa and A. nodosum. Botanica Marina, 35: 341349.

LITTLER, M.M. \& LITTLER, D.S. 1984. Models of tropical reef biogenesis: the contribution of algae. Progress on Phycological Research, 3: 323-364.

LOBBAN, C.S. \& HARRISON, P.J. 1997. Seaweed ecology and physiology. Cambridge University Press, Cambridge. 366p.

MAGGS, C.A. \& HOMMERSAND, M.H. 1993. Seaweeds of the British Isles. Rhodophyta: part A. Ceramiales. London, Natural History Museum. vol. 1. 444p.

MANSILLA, A.O. \& PEREIRA, S.M.B. 1998. Variação temporal da abundância e composição específica da macroflora associada a uma população de Sargassum (Fucophyceae) do litoral sul de Pernambuco, Brasil. Boletim de Botânica da Universidade de São Paulo, 17: 271-276.

MENCONI, M.; BENEDETTI-CECCHI, L. \& CINELLI, F. 1999. Spatial and temporal variability in the distribution of algae and invertebrates on rocky shores in the norwest Mediterranean. Journal of experimental marine Biology and Ecology, 233: 1-23.

MENGE, B.A. \& SUTHERLAND, J.P. 1976. Species diversity gradients: synthesis of the roles of predation, competition, and temporal heterogeneity. American Naturalist, 11: 351-369.

MUNIZ, R.A.; GONÇALVES, J.E.A. \& SZÉCHY, M.T.M. 2003. Variação temporal das macroalgas epífitas em
Sargassum vulgare C. Agardh (Phaeophyta-Fucales) da Prainha, Arraial do Cabo, Rio de Janeiro, Brazil. Iheringia, 58: 14-24.

NORTON, T.A. \& BURROWS, E.M. 1969. Studies on marine algae of the British Isles: Saccorhiza polyschides (Lightf.) Batt. British Phycological Journal, 4: 19-53.

OLIVEIRA FILHO, E.C. \& MAYAL, E.M. 1976. Seasonal variation of intertidal organisms at Ubatuba, São Paulo (Brazil). Revista Brasileira de Biologia, 36: 305-316.

PAULA, E.J. de. 1988. Gênero Sargassum C. Ag. (Phaeophyta-Fucales) no litoral do estado de São Paulo, Brasil. Boletim de Botânica da Universidade de São Paulo, 10: 65-118.

PAULA, E.J. de \& OLIVEIRA FILHO, E.C. 1980. Aspectos fenológicos de duas populações de Sargassum cymosum (Phaeophyta-Fucales) do litoral de São Paulo, Brasil. Boletim de Botânica da Universidade de São Paulo, 8: 21-39.

PAULA, E.J. de \& OLIVEIRA FILHO, E.C. 1982. Wave exposure and ecotypical differentiation in Sargassum cymosum (Phaeophyta- Fucales). Phycologia, 21: 145153.

PEARSON, G.A. \& EVANS, L.V. 1990. Settlement and survival of Polysiphonia lanosa (Ceramiales) spores on Ascophyllum nodosum and Fucus vesiculosus (Fucales). Journal of Phycology, 26: 597-603.

PEDRINI, A.G.; CASSANO, V.; COELHO, L.G. \& LABRONICI, G.J. 1994. Macroalgas marinhas da região sob influência da Central Nuclear Almirante Álvaro Alberto, Angra dos Reis, R.J., Brasil. I - Composição taxonômica. Pp 733-736. In: Anais do V Congresso Geral de Energia Nuclear. Rio de Janeiro. v. 2.

REIS, R.P.; LEAL, M.C.R.; YONESHIGUE-VALENTIN, Y. \& BELLUCO, F. 2003. Efeito de fatores bióticos no crescimento de Hypnea musciformis (Rhodophyta - Gigartinales). Acta Botanica Brasílica, 17: 279286.

RINDI, F. \& GUIRY, M.D. 2004. Composition and spatio temporal variability of the epiphytic macroalgal assemblage of Fucus vesiculosus Linnaeus at Clare Island, Mayo, western Ireland. Journal of experimental marine Biology and Ecology, 311: 233-252.

RÖNNBERG, O. \& RUOKOLAHTI, C. 1986. Seasonal variation of algal epiphytes and phenolic contents of Fucus vesiculosus in a northern Baltic Archipelago. Annales Botanica Fennicae, 23: 317-323.

ROUND, F.E. 1984. The ecology of algae. Cambridge University Press, Cambridge. 653p.

RULL, J. \& GARRETA, A.G. 1989. Distribución de las algas epífitas sobre los ejemplares de Cystoseira mediterranea Sauv. Anales del Jardin Botanico de Madrid, 46: 99-106.

STENECK, R.S. \& DETHIER, M.N. 1994. A functional group approach to the structure of algal dominated communities. Oikos, 69: 476-498.

STEWART, J.G. 1982. Anchor species and epiphytes in intertidal algal turf. Pacific Sciences, 36: 45-59.

SUARÉZ, A.M. 1985. Variación del epifitismo en Stypopodium zonale (Lamouroux) Papenfuss a lo 
largo de un año. Revista de Investigaciones Marinas, 10: 3-26.

SZÉCHY, M.T.M. 1996. Estrutura de bancos de Sargassum (Phaeophyta-Fucales) do litoral dos Estados do Rio de Janeiro e São Paulo. Tese de Doutorado, Instituto de Biociências, Universidade de São Paulo, 2 v.: $186+$ 159 p. São Paulo, Brasil.

SZÉCHY,M.T.M.; GALLIEZ,M.\& MARCONI, M.I. 2006. Quantitative variables applied to phenological studies on Sargassum vulgare C. Agardh (Phaeophyceae, Fucales) from Ilha Grande Bay, state of Rio de Janeiro. Revista Brasileira de Botânica, 29: 27-37.

SZÉCHY, M.T.M. \& NASSAR, C.A.G. 2005. Flora ficológica bentônica da Baía da Ribeira, sul do Estado do Rio de Janeiro: avaliação após duas décadas de operação da Central Nuclear Almirante Álvaro Alberto. Pp 373-397. In: R.C. Pereira, C.A.G. Nassar, M. Menezes \& V.L. Teixeira, (eds.), Formação de Ficólogos: um compromisso com a sustentabilidade dos recursos aquáticos. Museu Nacional, Rio de Janeiro. 562p.

SZÉCHY, M.T.M. \& PAULA, E.J. de. 1997. Macroalgas epífitas em Sargassum (Phaeophyta-Fucales) do litoral dos Estados do Rio de Janeiro e São Paulo, Brasil. Leandra, 12: 1-10.

SZÉCHY, M.T.M. \& PAULA, E.J. de. 2000a. Macroalgas associadas a bancos de Sargassum C. Agardh (Phaeophyta-Fucales) do litoral dos Estados do Rio de Janeiro e São Paulo, Brasil. Hoehnea, 27: 235-257.

SZÉCHY, M.T.M. \& PAULA, E.J. de. 2000b. Padrões estruturais quantitativos de bancos de Sargassum (Phaeophyta-Fucales) do litoral dos Estados do Rio de Janeiro e São Paulo, Brasil. Revista Brasileira de Botânica, 23: 121-132.

VALENTIN, J.L. 2000. Ecologia numérica: uma introdução à análise multivariada de dados ecológicos. Editora Interciência, Rio de Janeiro. 117p.

WILLIAMS, G.A. \& SEED, R. 1992. Interactions between macrofaunal epiphytes and their host algae. Pp 189212. In: D. John, S.J. Hawkins \& J. Price, (eds.), Plantanimal interactions in the marine benthos. Claredon Press, Oxford. 570pp.

WYNNE, M.J. 2005. A checklist of benthic marine algae of the tropical e subtropical western Atlantic: second revision. Nova Hedwigia, 129:1-152.

ZAR, J.H. 1984. Biostatistical analysis (Second edition). Prentice-Hall, New Jersey. 715p. 